\title{
Gérard de Nerval, Les Faux Saulniers. Histoire de l'abbé de Bucquoy
}

\section{Lise Sabourin}

\section{(2) OpenEdition}

1 Journals

\section{Édition électronique}

URL : http://journals.openedition.org/studifrancesi/6350

DOI : 10.4000/studifrancesi.6350

ISSN : 2421-5856

Éditeur

Rosenberg \& Sellier

\section{Édition imprimée}

Date de publication : 1 novembre 2010

Pagination : 568-569

ISSN : 0039-2944

\section{Référence électronique}

Lise Sabourin, "Gérard de Nerval, Les Faux Saulniers. Histoire de l'abbé de Bucquoy », Studi Francesi [En ligne], 162 (LIV | III) | 2010, mis en ligne le 30 novembre 2015, consulté le 07 janvier 2021. URL : http:// journals.openedition.org/studifrancesi/6350 ; DOI : https://doi.org/ERREUR PDO dans /localdata/ www-bin/Core/Core/Db/Db.class.php L.34 : SQLSTATE[HY000] [2006] MySQL server has gone away

Ce document a été généré automatiquement le 7 janvier 2021.

\section{(c) (†) $\ominus$}

Studi Francesi è distribuita con Licenza Creative Commons Attribuzione - Non commerciale - Non opere derivate 4.0 Internazionale. 


\title{
Gérard de Nerval, Les Faux Saulniers. Histoire de l'abbé de Bucquoy
}

\author{
Lise Sabourin
}

\section{RÉFÉRENCE}

GÉRARD DE NERVAL, Les Faux Saulniers. Histoire de l'abbé de Bucquoy, édition de Michel BRIX, Paris, Éditions du Sandre, 2009, pp. 275.

1 Les Faux Saulniers sont à la fois bien connus (car la matière en a été redistribuée dans Les Filles du Feu, Les Illuminés et même, brièvement, dans Lorely et La Bohême galante) et mal identifiés (certains passages n'ayant jamais été repris ailleurs), alors que le livre fonctionne comme un creuset pour les chefs-d'œuvre nervaliens et se révèle un modèle d'anti-roman à la Sterne en français.

2 Paru en feuilleton dans «Le National» du 24 octobre au 22 décembre 1850, il présente un récit «excentrique, capricieux et rhapsodique» (Introduction, p.10) qui se fait journal intime. En effet, se donnant pour prétexte la recherche d'un livre consacré à l'abbé de Bucquoy, à la suite de l'amendement Riancey sur la liberté de la presse (imposant redevance aux journaux qui publieraient des romans sans base historique), Nerval y développe des considérations sur l'autobiographie moderne et le rôle de l'écrivain dans la société en une sorte d'essai à la «rédaction décousue, spontanée, discontinue, improvisée» (p. 9). Tout en s'interrogeant sur les frontières entre histoire et fiction, la quête se mue en causeries, avec digressions et incidentes, allusions littéraires, impressions de lectures, récits de souvenirs et épisodes cocasses, comptes rendus de flâneries dans le Valois au hasard des sensations.

3 S'inscrivant dans le courant fantaisiste après Stendhal et Nodier en réaction au pindarisme engagé des romantiques, Nerval, comme Gautier et Champfleury, veut réconcilier l'art avec la vie quotidienne et juge son inspiration personnelle plus capable de parler aux citoyens de «moyen état». Après Le Marquis de Fayolle avorté en 1849 qui a signé sa difficulté d'imaginaire hors des récits de voyage et des comptes rendus 
dramatiques, l'essayiste en revient donc à l'autobiographie (d'autant mieux venue qu'un autre amendement Tinguy a obligé à signer les articles de presse sans pseudonyme ni anonymat): d'ailleurs cela plaît d'autant plus au public que son internement récent a attiré l'attention sur sa personnalité.

4 Mais il en profite aussi pour exprimer les protestations du journal républicain auquel il collabore contre les lois répressives qui préparent le coup d'État: la figure de l'abbé Bucquoy, souvent emprisonné sous l'Ancien Régime, constitue un support adéquat à une réflexion sur l'arbitraire, suggérant les dérives analogues qui pourraient être provoquées par l'autoritarisme. La fable du ciron qui, comme les Valoisiens sous les Bourbons, ronge subrepticement le trône royal s'ajoute aux pages malicieuses sur les documents mal classés dans les bibliothèques ou les archives devenues inaccessibles pour fournie des sources aux romans. Nerval, dénonçant en fait le mensonge entretenu par les abus de pouvoir, appelle comme Vigny les gens de lettres à prendre le relais de l'aristocratie en déclin depuis Henri IV en se constituant en rempart contre la tyrannie afin de prévenir les troubles sociaux qui pourraient naître d'un tel déni diffus de justice et d'équité.

5 Comme à son habitude, Michel Brix nous délivre une belle édition critique, avec une forte introduction (pp. 7-32) et des notes précieuses (pp. 229-274). 